\title{
An analysis of the impact of an advanced aero-hydro-servo-elastic model of dynamics on the generator-converter dynamics, for an offshore fixed 5MW PMSG wind turbine
}

\author{
J Carmona-Sanchez*, Z Lin L $^{\dagger}$ M Collu ${ }^{\dagger}$, M Barnes*, O Marjanovic*, D Cevasco ${ }^{\dagger \dagger}$ \\ *School of Electrical \& Electronic Engineering, University of Manchester, Manchester, UK, + Department of Naval Architecture, Ocean and Marine \\ Engineering, University of Strathclyde, Glasgow, UK, $\dagger+$ Offshore Energy Engineering Centre-REMS CDT, Cranfield University, UK.
}

Keywords: PMSG, Aero-Hydro-Servo-Elastic, Wind Turbine, Direct Drive, Electromechanically Dynamics, Pitch Control, Coupled analysis

\begin{abstract}
This paper gives a comparative analysis of the performance of a wind turbine direct drive train system with PMSG and fully rated converters when two different wind turbine models are used for its assessment. The impact of the advanced AeroHydro-Servo-Elastic model, and the most common analytical function wind turbine model, on the generator-converter dynamics are assessed. Results corresponding to the system response to steps up/down in wind speed and turbulent wind speed conditions are presented and discussed in the paper. It is found that below rated speed there is no significant difference between results obtained from both models. Above rated wind speed there exist some differences among results.
\end{abstract}

\section{Introduction}

The UK wind power installed capacity is expected to rise from $20 \mathrm{GW}$ [1] to $40 \mathrm{GW}$ in the next few decades with an estimated initial capital cost of $£ 120$ billion and with an operation and maintenance (O\&M) industry worth of $£ 2$ billion per year by 2025 [2]. The UK has the largest offshore wind resource in Europe, which is estimated to be a third of the total European offshore wind resource [3]. As of May 2018, there were 36 offshore wind energy operational power stations representing 7GW of installed capacity in the UK [4]. Many of these power stations use high voltage AC (HVAC) technology to transmit the energy from offshore to main land. However, many future offshore wind farms will be very far from mainland, as an example, Dogger Bank, contemplated for UK Round 3, is located 125-290 km from the UK shore. Traditional AC transmission systems would be uneconomical

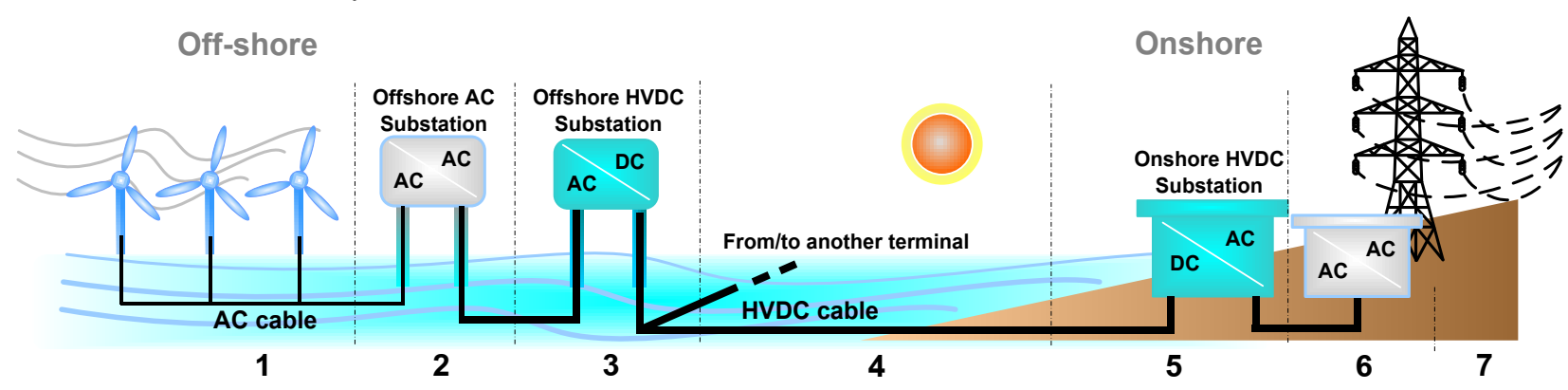

Fig. 1: Offshore wind power generation interfaced to the AC systems by VSC-HVDC transmission. and practically unfeasible at this distance [5]; requiring deployment of HVDC transmission for such projects. Fig. 1 outlines the typical hardware configuration used to interface offshore wind power generation to AC systems by means of VSC-HVDC transmission technology. Wind farm turbine locations, Stage 1 in Fig. 1, are chosen according to strong and stable wind conditions [6]. The offshore substations/platforms are intended to be unmanned, operated from onshore [3] and visited infrequently. Harsh weather can make it difficult to inspect and perform maintenance on both turbines and substations [6]. Even if there are favourable weather conditions, transport of personnel to/from offshore substations implies high costs [6]. O\&M of such substations accounts for approximately $20-25 \%$ of their total life-time costs [7] compared to $10 \%-15 \%$ of onshore substations [6]. Therefore, the use of predictive maintenance could allow scheduling minor repairs to prevent major work and subsequently enhance the reliability and achieve better costeffective O\&M practices for such systems. For model driven predictive maintenance, a simple yet realistic/accurate model of the system's components and coupled electromechanical dynamics is critical given that aging and system's failures are strongly related to thermal cycling, vibration and electrical stresses. Of particular interest are the wind turbine electric generator and its corresponding AC/DC converters. Regarding this, the wind energy industry is already very aware of best condition monitoring (CM) and O\&M practices for present systems such as:

- Type 1: Fixed speed wind turbines

- Type 2: Limited variable-speed wind turbines (variable slip-resistors)

- Type 3: Variable speed wind turbines with partialscale power converter

Fig. 1: Offshore wind power generation interfaced to the AC systems by VSC-HVDC transmission. 


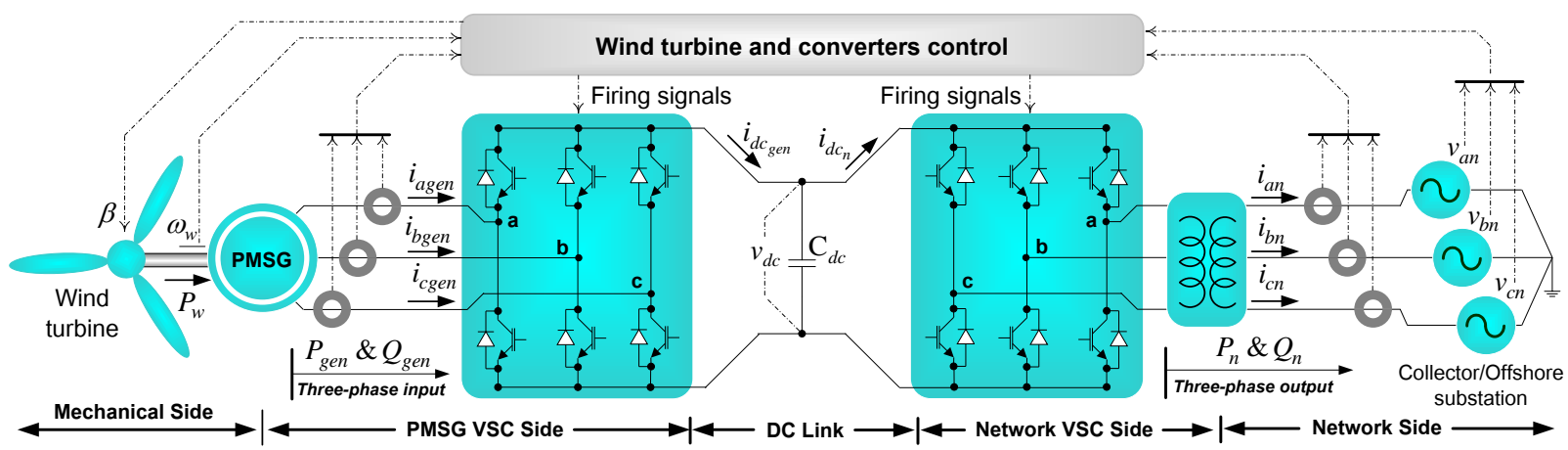

Figure 2: Variable-speed wind turbine direct-drive-train PMSG with full rated VSCs - without gearbox (Type 4)

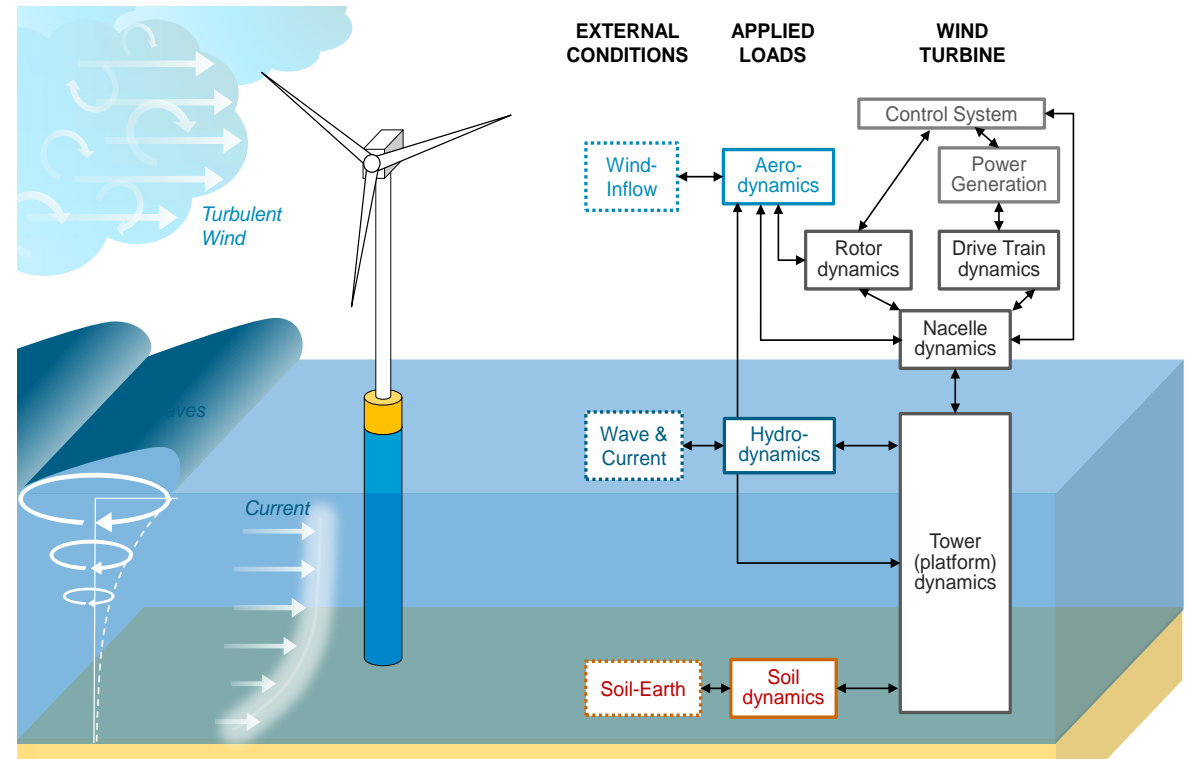

Figure 3: Offshore wind turbine dynamics - bottom-fixed. Such dynamics are also the ones considered by the AHSE model (Adapted from [15]).

Hence, this paper focuses on the analysis of future systems to be used in 5+ years, i.e. Type 4 (outlined in Fig. 2):

- Type 4: Variable speed wind turbines with full-scale power converter with and without gearbox.

For Type 4 systems, the present leading electric generator technology is/will likely be the permanent magnet synchronous generator (PMSG) [8] which is the one used in this paper. One of the most comprehensive offshore wind turbine modelling approaches is the aero-hydro-servo-elastic (AHSE) modelling which captures a very wide range of dynamics that accurately describe the wind turbine in the real world. However, detailed wind turbine models, such as the AHSE model, have been mainly used for wind turbine design purposes, generally coupling geared drive-train with a doubly-fed induction generator (DFIG) and partially rated back-to-back converters. Little research has focused on the dynamics of the AHSE wind turbine model coupled via a direct-drive-train with permanent magnet synchronous generator (PMSG) and full rated back-to-back converters. In fact, to the best of the authors' knowledge there are only two papers that considers this case [9]-[10]. Furthermore, the most common wind turbine aerodynamic model found in the literature [11]-[12], and used for the assessment of the wind turbine and its associated electric generator and converters, provides expression of generated mechanical power as an analytical function of pitch angle, wind speed and turbine speed. This analytical wind turbine model (AWTM) is described in Subsection 2.2 of this paper. The use of a very simplified wind turbine model, such as the AWTM, might render misleading dynamic responses of the system to real world disturbances. Hence, a comparative analysis and results of the Type 4 system, when the AHSE and AFWT models are used for its assessment, are presented in Section 4 of this paper.

\section{Wind Turbine Direct Drive Train Model and its Control}

In the wind turbine direct-drive train topology shown in Fig. 2, the wind turbine converts the kinetic energy from the wind to mechanical energy. The mechanical energy is then transformed to electric energy by the electric generator (i.e. PMSG). This energy is finally converted/regulated by the voltage source converters (VSC) to the appropriate electric levels to be injected to the grid-collector. The next sections of the paper describe the model of each component used for the assessment of such system. 


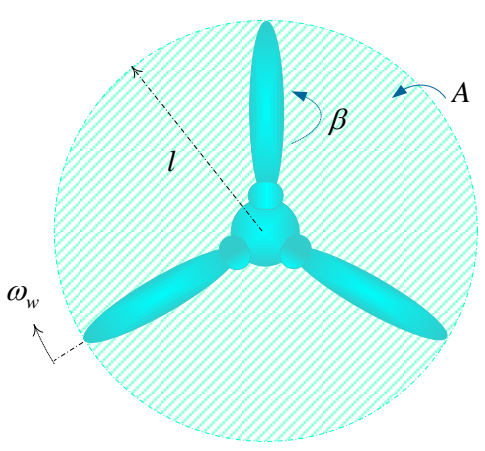

Wind turbine front view

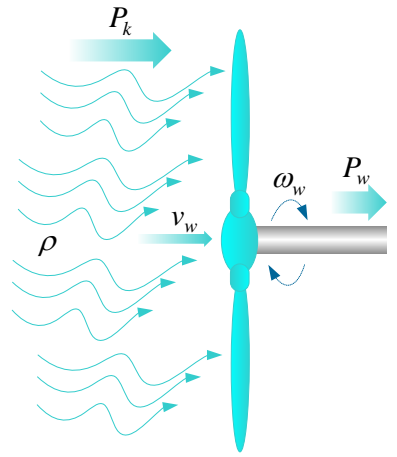

Wind turbine side view

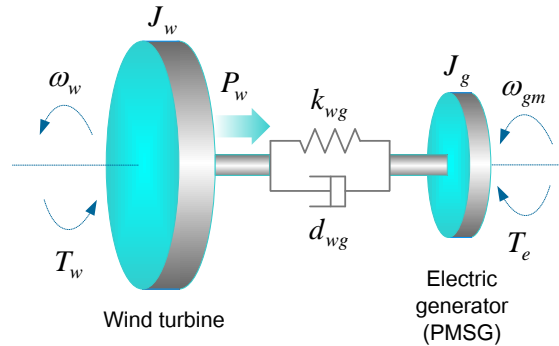

Figure 4: Wind turbine elements-components considered in the AFWT model (left) and two-mass mechanical drive train model (right).

\subsection{Wind Turbine Modelling}

\subsubsection{Aero-Hydro-Servo-Elastic (AHSE) Wind Turbine Model}

For accurate assessment of offshore wind turbines (OWTs) performance, consideration of the stochastic nature of the aerodynamic and hydrodynamic loads acting on the wind turbine is paramount. Modelling of the mechanical aspects of OWTs encompasses consideration of aero, hydro and structure dynamics [13] as well as the non-linear dynamics of the main mechanical components, such as blades, hub, low and high speed shafts, gearbox, etc., as exemplified in Fig. 3. Within the present work, the dynamics of these stochastic loads and of the wind turbine mechanical components are modelled using a state-of-the-art AHSE model of dynamics by FAST-NREL [14]. Figure 3 shows an overview of the modules and capabilities of this AHSE model, and detailed information can be found in [15]. For the purpose of this paper, the AHSE model of FAST is coupled, through the shaft, whit the direct-drive-train PMSG with full rated VSCs (type 4) already introduced in Fig. 2.

\subsubsection{Analytical Function Wind Turbine (AFWT) Model}

In the most common and widely used wind turbine model found in the literature, the non-linear dynamics of the wind turbine are substantially simplified down to an analytical function of blade pitch angle ( $\beta$ in degrees), wind speed $\left(v_{w}\right.$ in $\left.\mathrm{m} / \mathrm{s}\right)$ and turbine angular speed $\left(\omega_{w}\right.$ in $\left.\mathrm{rad} / \mathrm{s}\right)$ as given by (1)-(5) [11]-[12]. In (1), $P_{k}$ is the total kinetic power, in watts, available from the wind entering the wind turbine rotor as shown in Fig. 4. $A$ is the turbine swept area in $\mathrm{m}^{2} . \rho$ is the air density in $\mathrm{kg} / \mathrm{m}^{3}$. The actual captured power, i.e. shaft power $P_{w}$, from the wind is obtained by considering the power conversion coefficient $C_{P}$ as given by (2), where $l$ is the turbine radius in meters. The analytical expression for $C_{P}$ is as given by (3), where $\lambda$ is the tip speed ratio as given by (5). The mechanical torque corresponding to the captured power at a given $v_{w}$ and $\omega_{w}$ is defined by (6).

$$
\begin{aligned}
& P_{k}=\frac{1}{2} \rho A v_{w}^{3} \\
& P_{w}=\frac{1}{2} \rho \pi l^{2} v_{w}^{3} C_{P}
\end{aligned}
$$

$$
\begin{aligned}
& C_{P}=0.5176\left(\frac{116}{\lambda_{i}}-0.4 \beta-5\right) e^{\frac{-21}{\lambda_{i}}}+0.0068 \lambda \\
& \frac{1}{\lambda_{i}}=\frac{1}{\lambda+0.008 \beta}-\frac{0.035}{\beta^{3}+1} \\
& \lambda=\frac{l \omega_{w}}{v_{w}} \\
& T_{w}=\frac{1}{2 \omega_{w}} \rho \pi l^{2} v_{w}^{3} C_{P} \\
& J_{w} \frac{d \omega_{w}}{d t}=T_{w}-k_{w g} \theta_{w g}-d_{w g} \frac{d \theta_{w g}}{d t} \\
& J_{g} \frac{d \omega_{g m}}{d t}=k_{w g} \theta_{w g}+d_{w g} \frac{d \theta_{w g}}{d t}-T_{e} \\
& \frac{d \theta_{w g}}{d t}=\omega_{w}-\omega_{g m}
\end{aligned}
$$

To account for the inertia of the wind turbine $J_{w}$, electric generator rotor inertia $J_{g}$ and the mechanical drive train dynamics, the torque given by (6) is usually coupled to single or two-mass models. In this paper, a two-mass model (as outlined in Fig. 4), which completes the AFWT model, is implemented as given by (7)-(9), where $k_{w g}$ and $d_{w g}$ represent the stiffness and damping of the shaft and $\omega_{g m}$ is the electric generator mechanical angular speed [12][16].

\subsection{PMSG, Generator-Side-VSC and Control System Modelling}

The PMSG electric dynamics are modelled by the wellknown $q d$ model given by (10)-(11), where $L_{q}$ and $L_{d}$ are the generator stator $q$ and $d$ axes inductances respectively and $R$ represents the stator resistance.

$$
\begin{aligned}
& L_{d} \frac{d i_{d}}{d t}=v_{d}-R i_{d}+\omega_{g e} L_{q} i_{q} \\
& L_{q} \frac{d i_{q}}{d t}=v_{q}-R i_{q}-\omega_{g e} L_{d} i_{d}-\omega_{g e} \lambda_{m} \\
& \omega_{g e}=p_{p} \omega_{g m} \\
& T_{e}=\left(\frac{3}{2}\right) p_{p}\left[\lambda_{m} i_{q}+\left(L_{d}-L_{q}\right) i_{d} i_{q}\right]
\end{aligned}
$$

The relationship between generator mechanical and electrical $\left(\omega_{g e}\right)$ angular speed is given by (12), where $p_{p}$ represents 


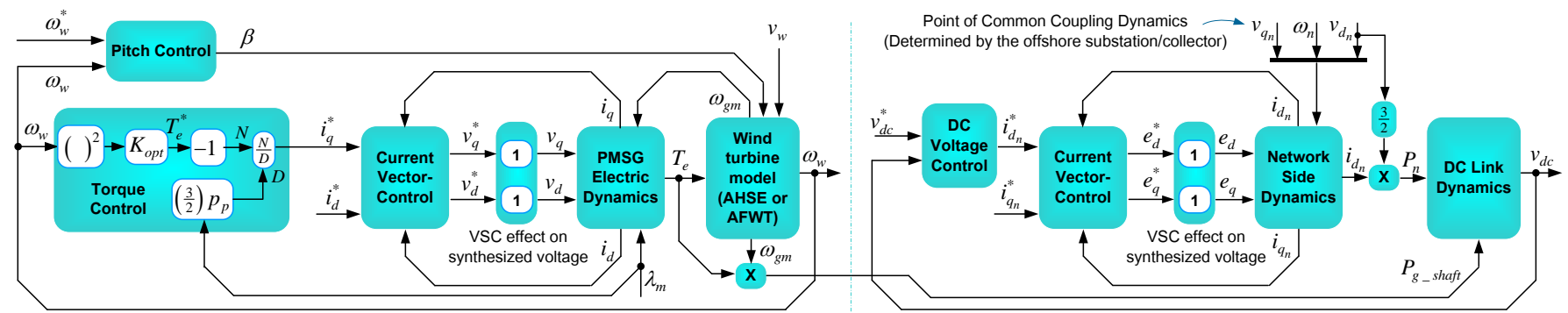

Figure 5: Wind turbine direct drive train model and control integration layout.

the pole-pairs of the generator. The generator electric torque $\left(T_{e}\right)$, with magnetic flux $\lambda_{m}$, can be obtained as given by (13). Equations (12) and (13) allow coupling between the generator electric dynamics and the shaft dynamics, i.e. the two-mass model given by (7)-(9).

Control of the PMSG is achieved by vector control as outlined in Fig.5. The function of the VSC is to synthesise the desired stator voltage, i.e. $v_{d}^{*}$ and $v_{q}^{*}$, to be applied to the PMSG in order to achieve the desired current, i.e. $i_{d}^{*}$ and $i_{q}^{*}$. The VSC involves very high-order low-loss dynamics compared to the PMSG dynamics. Therefore $v_{d}^{*} \approx v_{d}$ and $v_{q}^{*} \approx v_{q}$. The design of the current vector control shown in Fig.5 is a very well know procedure, therefore, it is not repeated here.

\subsection{Network Side Dynamics, Network-Side-VSC and Control System Modelling}

The network side electric dynamics are modelled in the $d q$ frame as given by (14)-(15), where $L_{n}$ and $R_{n}$ are the equivalent series inductance and resistance of the link interconnecting the VSC and collector. Variables $e_{d}$ and $e_{q}$ represent the VSC output voltage and $v_{d_{n}}$ and $v_{q_{n}}$ represent the network voltage. Control of the current injected to the network by the VSC, i.e. $i_{q_{n}}$ and $i_{d_{n}}$, is achieved by vector control as shown in Fig. 5.

$$
\begin{aligned}
& e_{d}-v_{d_{n}}=R_{n} i_{d_{n}}+L_{n} \frac{d i_{d_{n}}}{d t}-\omega_{n} L_{n} i_{q_{n}} \\
& e_{q}-v_{q_{n}}=R_{n} i_{q_{n}}+L_{n} \frac{d i_{q_{n}}}{d t}+\omega_{n} L_{n} i_{d_{n}}
\end{aligned}
$$

\subsection{Link Dynamics and Control}

One of the most important dynamics to be considered in the analysis of a wind turbine direct drive train with full rated converters is the DC link dynamic model which in this paper is given by (16).

$$
\begin{aligned}
& C \frac{d v_{d c}}{d t}=i_{d c_{g e n}}-i_{d c_{n}} \\
& v_{d c} C \frac{d v_{d c}}{d t}=P_{d c_{-} g e n}-P_{d c_{-} n} \\
& P_{d c_{-} n}=v_{d c} i_{d c_{n}} \approx P_{n}=\frac{3}{2} v_{d_{n}} i_{d_{n}} \\
& P_{d c_{-} g e n}=v_{d c} i_{d c_{g e n}} \approx P_{g_{-} \text {shaft }}=\omega_{g m} T_{e}
\end{aligned}
$$

In (16), $v_{d c}$ is the DC voltage, $i_{d c_{g e n}}$ is the DC current injected to the DC link by the VSC at the PMSG side, $i_{d c_{n}}$ is the DC current drawn from the DC link by the VSC at the Network side and $C$ is the equivalent capacitance. The DC link dynamic model expressed in terms of power is obtained by multiplying (16) by $v_{d c}$ as given by (17). Further, by assuming lossless VSCs, the relationship among the generator shaft power $P_{g_{s} s h a f t}, v_{d c}$ and the power inject to the network $P_{n}$ is obtained as stated by (17)-(19). Control of the DC voltage is achieved by vector control. Detailed description of the control design is not given in this paper since it is a wellknown procedure. However, careful attention must be paid to the selection of the capacitance to be used for the design and control of the DC link. In this paper, the recommendations given in [17] were followed.

\subsection{Wind Turbine Power and Pitch control}

The function of the PMSG is to convert the wind turbine power to electric power. Maximum power point tracking of the wind turbine can be achieved as stated by (20)-(21) [11], where $P_{w_{\text {track }}}$ is the maximum tracked wind turbine power at different wind speeds, $T_{e}^{*}$ is the desired PMSG torque and $K_{o p t}$ is a constant. $K_{o p t}$ can be calculated from (2) and (5) by keeping $\lambda$ and $C_{P}$ constant and equal to their optimal values. The PMSG control torque, outlined in Fig. 5, is based on (21). Thus power is indirectly tracked by controlling torque.

$$
\begin{aligned}
& P_{w_{\text {track }}}=K_{o p t} \omega_{w}^{3}=\omega_{w} T_{e}^{*} \\
& T_{e}^{*}=K_{o p t} \omega_{w}^{2}
\end{aligned}
$$

Pitch control is implemented to deal with wind speeds that exceed the rated wind speed of the turbine, as outlined in the Fig. 5. The pitch control remains inactive for angular wind turbine speeds $\left(\omega_{w}\right)$ lower than the rated speed. Detailed information regarding the pitch control design can be found in [18].

\section{Verification of the AHSE Direct Drive Train Model with PMSG vs. the Geared NREL Model with Induction Generator}

Verification of the AHSE model with direct-drive train PMSG, shown in Fig. 6, was carried out by comparing the results obtained with the system model described in Section 2.1.1 of this paper and the results given in [18] for the NREL offshore 5-MW baseline wind turbine. The NREL wind turbine is a conventional three-bladed upwind variable-speed variable blade-pitch-to-feather-controlled turbine with 


\begin{tabular}{c|c|c|c}
\hline Power & Rotor Diameter & Rated wind speed & Rotor speed \\
\hline $5 \mathrm{MW}$ & $126 \mathrm{~m}$ & $11.4 \mathrm{~m} / \mathrm{s}$ & $\begin{array}{c}12.1 \mathrm{rpm} \\
(1.267 \mathrm{rad} / \mathrm{s})\end{array}$ \\
\hline
\end{tabular}

Table 1: Wind turbine rated parameters

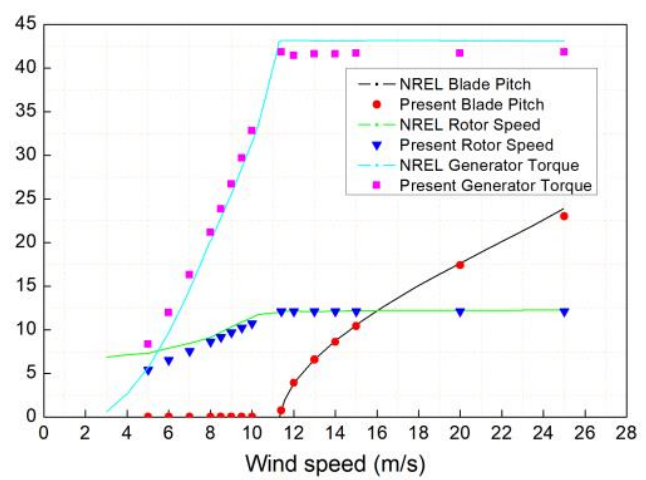

Figure 6: Results of the present AHSE wind turbine direct-drive train with PMSG versus results of the NREL offshore 5-MW baseline wind turbine [18] presented in page 32 .

induction generator. The rated parameters are as given in Table 1. Further details for the wind turbine can be found in [18]. Parameters used in this paper for the PMSG were adapted from [19]. It can be observed in Fig. 6 that there is close match between results obtained with the present model and those presented in [18] for torque, rotor speed and blade pitch angle under a wind speed range of $5 \mathrm{~m} / \mathrm{s}$ to $15 \mathrm{~m} / \mathrm{s}$, steady wind conditions.

\section{Case study - Performance of the AHSE vs the AFWT Direct-Drive Train with PMSG}

The dynamic system response was assessed under three different scenarios. First the system was subjected to a stepdown in wind speed from $11.4 \mathrm{~m} / \mathrm{s}$ to $8.5 \mathrm{~m} / \mathrm{s}$ with results shown in Figs. 7a-h. As observed, the response of the system under this condition is the same for both AHSE and AFWT models. Since the pitch angle is kept to zero, results shown in Figs. 8a-h suggest that the AFWT model provides an accurate representation of the relationship among wind speed, wind turbine speed and torque/power.

The system was also tested under a step-up in wind speed from $11.4 \mathrm{~m} / \mathrm{s}$ to $12.5 \mathrm{~m} / \mathrm{s}$ with comparative results shown in Figs. 7aa-hh. As observed in Figs.7aa-hh, there exist deviations under transient conditions between results obtained from AHSE and AFWT models. Although, both systems reach the same wind turbine speed, power and torque, there is a significant difference between the pitch angle obtained from the AHSE model and that corresponding to the AFWT model. This can be explained by the fact that when using the AFWT model there could be an identical value of $C_{P}$ for the same tip speed ratio $\lambda$ but a different pitch angle, as explained in [20]. The generic AFWT model could be adjusted to meet the characteristics of a specific wind turbine, which in theory would imply to be adjusted to match the AHSE model. However, this is a highly time consuming task that requires considerable effort, "even for those with a long experience of performing such approximations" [20]. Results presented in Fig. 7 and 8 , can be considered as example of the

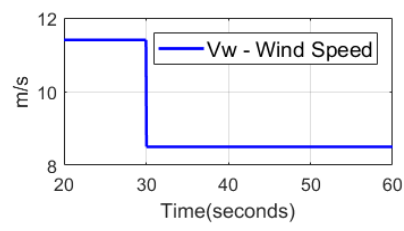

a) Wind speed

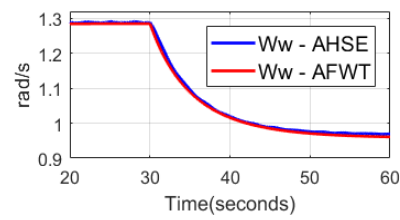

b) Wind turbine speed

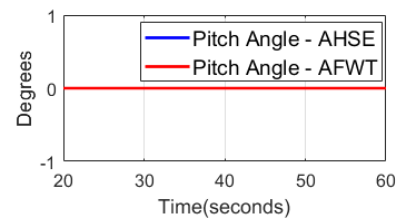

c) Pitch angle

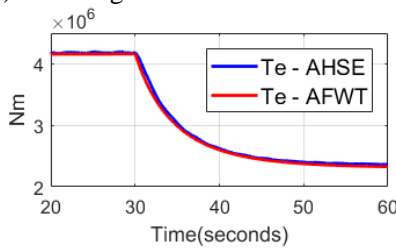

d) Electric torque

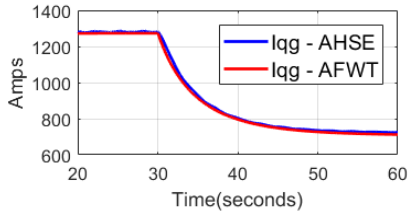

e) PMSG q-axis current

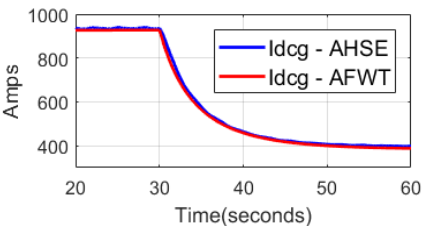

f) PMSG-converter dc current

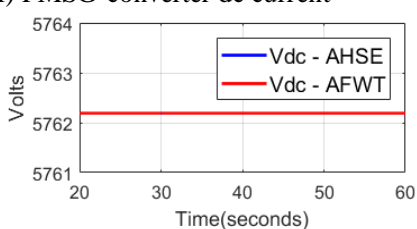

g) DC voltage

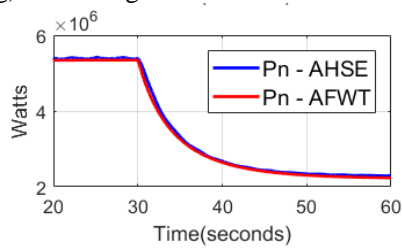

h) Injected network power

Fig. 7: System response to a step up and down in wind speed. a)-h) Response to a step down in wind speed from $11.4 \mathrm{~m} / \mathrm{s}$ to $8.5 \mathrm{~m} / \mathrm{s}$ at $30 \mathrm{~s}$ and aa)-hh) Response to a step up in wind speed from $11.4 \mathrm{~m} / \mathrm{s}$ to $12.5 \mathrm{~m} / \mathrm{s}$ at $30 \mathrm{~s}$.

discrepancies that can be found among results when evaluating a wind turbine direct drive train system with a typical AFWT model and those obtained with a more 

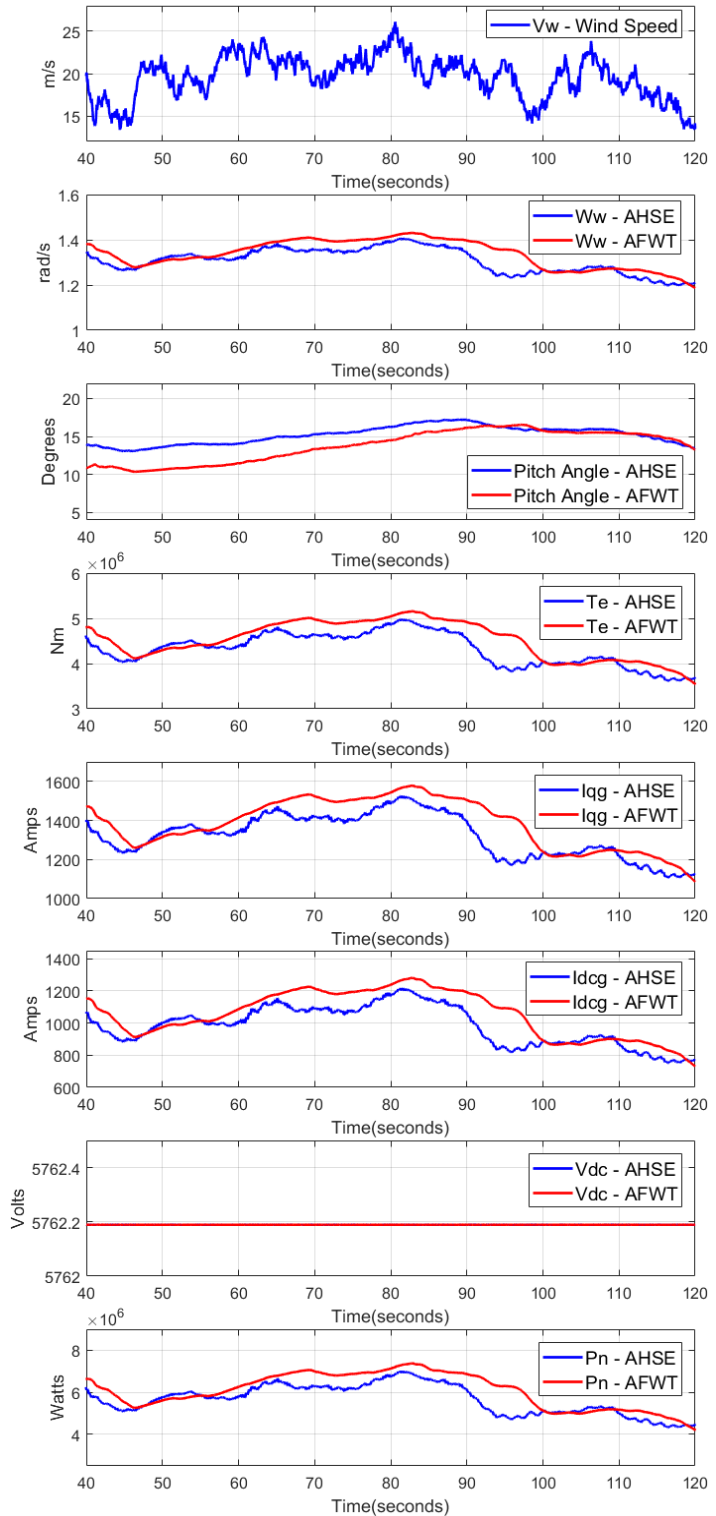

Fig. 8: System response to turbulent wind conditions

complete wind turbine model such as the AHSE model.

Furthermore, the system was tested under turbulent wind conditions with comparative results presented in Fig. 8. Differences in results can be explained by the discussion given in the previous paragraph. As can be observed, the pitch control attempts to keep the wind turbine speed constant at the rated value whilst maximum optimum power tracking is attempted. However, both constraints cannot be met under these circumstances. Of particular interest is that the DC voltage is virtually unaffected even under these very high transient conditions.

\section{Conclusions}

The AHSE model is one of the most complete wind turbine models currently available. However, it is very computational intensive. Simpler AFWT models are less computationally intensive. However, they might not be able to represent an accurate relationship among the wind turbine variables under some circumstances; especially above rated wind speed.
Furthermore, although typical AFWT models consider the relationship among wind speed, turbine speed and pitch angle which might be sufficient for an onshore wind turbine representation, for an offshore wind turbine, consideration of the hydrodynamics might be paramount.

In this work, the stochastic nature of the wind has been taken into account. Future work will look at integrating also stochastic wave loads (i.e. hydrodynamics) which are important dynamics to be considered in operational conditions for floating offshore wind turbines.

\section{Acknowledgements}

This work was supported by the Engineering and Physical Sciences Research Council (EPSRC) through grants EP/P009743/1 and EP/L021463/1. The last author is also supported by grant EP/L016303/1. The authors would like to acknowledge EngD student Dawn Ward for her help in the pitch control implementation.

\section{References}

[1] RenewableUK. "Wind Energy Statistics". Accessed on 11/09/2018: https://www. renewableuk.com/page/UKWEDhome

[2] Home Offshore. "Technology Drivers in Windfarm Asset Management". Position Paper, 2018.

[3] The Crown Estate. "Transmission Infrastructure Associated with Connecting Offshore Generation". 2013. Available at: https://www.transmissioninfrastructureoffshoregen.co.uk/media/9384/the_crown_estate_transmission_infrastructure_print _april.pdf

[4] Department for Business, Energy \& Industrial Strategy. "Digest of UK Energy Statistics (DUKES) 2018: main report". National Statistics, GOV.UK, July 2018.

[5] C. Maciver and K.R.W. Bell. "Reliability Analysis of Design Options for Offshore HVDC Networks". Paper presented at 2014 CIGRE Session, Paris, France.

[6] Øyvind Netland. "Remote Inspection of Offshore Wind Turbines: A Study of the Benefits, Usability and Feasibility". Doctoral Theses. Norwegian University of Science and Technology. Faculty of Information Technology, Mathematics and Electrical Engineering Department of Engineering Cybernetics. 2014.

[7] "Scottish Enterprise" and "The Crown State". "A Guide to UK Offshore Wind Operations and Maintenance". 2013.

[8] Carroll, J., McDonald, A., Dinwoodie, I., McMillan, D., Revie, M., and Lazakis, I. "Availability, operation and maintenance costs of offshore wind turbines with different drive train configurations". Wind Energ., 2017, 20: 361-378.

[9] A. Hemeida, A. A. Farag, and O. A. Mahgoub, "Modeling and control of direct driven PMSG for ultra large wind turbines," World Academy of Science, Engineering and Technology, vol. 59, pp. 918-924, 2011.

[10] D. S. Ochs, R. D. Miller and W. N. White, "Simulation of Electromechanical Interactions of Permanent-Magnet Direct-Drive Wind Turbines Using the FAST Aeroelastic Simulator," in IEEE Transactions on Sustainable Energy, vol. 5, no. 1, pp. 2-9, Jan. 2014.

[11] Y. Xia, K. H. Ahmed and B. W. Williams, "Wind Turbine Power Coefficient Analysis of a New Maximum Power Point Tracking Technique," in IEEE Transactions on Industrial Electronics, vol. 60, no. 3, pp. 1122-1132, March 2013.

[12] Ye, H., Yue, B., Li, X., and Strunz, K. "Modelling and simulation of multi-scale transients for PMSG-based wind power systems". Wind Energ. 2017, 20: 1349 1364.

[13] Bing Feng Ng, Rafael Palacios \& J. Michael R. Graham. "Model-based aeroelastic analysis and blade load alleviation of offshore wind turbines", International Journal of Control, Vol. 90, No. 1, pages 15-36. Taylor \& Francis, 2017.

[14] NWTC Information Portal (FAST v8). https://nwtc.nrel.gov/FAST8. Last modified 04-January-2018; Accessed 10-September-2018

[15] Jonkman, J.M. 2013, "The new modularization framework for the FAST wind turbine CAE tool", 51st AIAA Aerospace Sciences Meeting including the New Horizons Forum and Aerospace Exposition 2013.

[16] S. M. Muyeen, M. H. Ali, R. Takahashi, T. Murata, J. Tamura, Y. Tomaki, A. Sakahara, and E. Sasano, "Comparative study on transient stability analysis of wind turbine generator system using different drive train models," IET Renewable Power Generation, vol. 1(2), pp. 131-141, 2007

[17] Hansen, A. D. and Michalke, G. "Modelling and control of variable-speed multipole permanent magnet synchronous generator wind turbine". Wind Energ. 2008 , 11: 537-554.

[18] J. Jonkman, S. Butterfield, W. Musial, and G. Scott. "Definition of a 5-MW Reference Wind Turbine for Offshore System Development". Technical Report NREL/TP-500 38060, February 2009.

[19] J. Zhang, Z. Chen and M. Cheng, "Design and comparison of a novel stator interior permanent magnet generator for direct-drive wind turbines," in IET Renewable Power Generation, vol. 1, no. 4, pp. 203-210, December 2007.

[20] S. Heier. "Grid integration of wind energy onshore and offshore conversion systems". Third Edition, John Wiley \& Sons Ltd, 2014. 